\title{
Buitenlandse keuzestage in de specialistenopleiding van de baan?
}

\author{
D.H. Visser, E.A.M. Westerbeek, L.H. Hendrikx, J.O. Busari, B.H.M. Wolf
}

\begin{abstract}
Samenvatting
De medisch specialistenopleidingen worden geherstructureerd en sinds begin 2007 door een speciaal Opleidingsfonds van het ministerie van VWS gefinancierd. Recent heeft het ministerie van VWS eenzijdig besloten de buitenlandse keuzestages in de medische vervolgopleidingen buiten de vergoeding van het Opleidingfonds te houden. Dit maakt het voor een groot aantal specialisten in opleiding onmogelijk om een keuzestage in het buitenland te doen. Een enquête onder alle kinderartsen in opleiding in Nederland in januari 2009 toont aan dat 99\% een buitenlandse keuzestage ziet als een verrijking van de opleiding tot specialist. Een groot deel van de artsen in opleiding tot specialist (aios) kindergeneeskunde is het dan ook niet eens met de maatregel van het ministerie van VWS, die belemmerend werkt op de professionele vorming van de toekomstige specialist. (Visser DH, Westerbeek EAM, Hendrikx LH, Busari JO, Wolf BHM. Buitenlandse keuzestage in de specialistenopleiding van de baan? Tijdschrift voor Medisch Onderwijs 2009;28(3):119-123.)
\end{abstract}

\section{Inleiding}

Vanaf 2007 worden op grond van de subsidieregeling 'zorgopleidingen $1^{\mathrm{e}}$ tranche' de vervolgopleidingen voor medisch specialisten gefinancierd uit het Opleidingsfonds van het ministerie van VWS. Voorheen namen zorginstellingen de opleidingskosten van artsen in opleiding tot specialist (aios) mee in de onderhandelingen met zorgverzekeraars en leidde het opleiden van aios tot hogere tarieven, hetgeen marktverstorend werkte. Met de komst van het Opleidingsfonds zijn de budgetten van de ziekenhuizen geschoond van het onderdeel opleidingen en ontvangen zij rechtstreeks uit het Opleidingfonds van VWS voor elke aios een vergoeding.

Echter, sinds eind 2007 worden buitenlandse stages als onderdeel van de opleiding tot medisch specialist niet langer door het Opleidingsfonds gefinancierd. De kwaliteit van de medische vervolgopleidingen en de professionele vorming van de toekomstige specialist komen hiermee in het gedrang.

\section{VWS beëindigt financiering buiten- landse keuzestages}

Eind 2007 is door het ministerie van VWS besloten dat een instellingssubsidie nog uitsluitend wordt verstrekt aan nationale instellingen voor medisch specialistische zorg, zijnde algemene ziekenhuizen, academische ziekenhuizen, instellingen voor revalidatie of andere door de minister aan te wijzen instellingen. Subsidies voor stages in buitenlandse instellingen, ook als die voldoen aan de kwaliteitseisen van het Centraal College Medische Specialismen (CCMS), worden niet langer door het Opleidingsfonds verstrekt. ${ }^{1-2}$ Indien de aios, in samenspraak met zijn opleider, toch besluit een door de Medisch Specialisten Registratie Commissie (MSRC) erkende stage in het buitenland te doen, zal de instellingssubsidie, op jaarbasis verstrekt 
door het Opleidingsfonds, worden verminderd met het aantal uren dat de aios niet werkzaam is geweest in een Nederlandse instelling. ${ }^{2}$ Een buitenlandse stage als onderdeel van de medische vervolgopleiding zal in dat geval volledig moeten worden gefinancierd door de aios zelf, wat de realisatie van een dergelijke stage in feite onmogelijk maakt.

\section{Herstructurering specialisten- opleidingen}

Naar aanleiding van de rapporten 'De arts van straks' en 'De zorg van morgen'3-4 is binnen de specialistenopleidingen een herstructurering in gang gezet met als doel de kwaliteit van de medische vervolgopleidingen te verbeteren. Belangrijk bij deze herstructurering is dat de vervolgopleidingen worden gebaseerd op het raamwerk van de zeven CanMEDS competenties (medisch handelen, communicatie, samenwerking, organisatie, kennis en wetenschap, maatschappelijk handelen, professionaliteit). Bij de implementatie van de nieuwe opleidingsplannen hebben de vakgroepen Obstetrie \& Gynaecologie en Kindergeneeskunde het voortouw genomen met het in 2006 gestarte project 'Vaart in de Innovatie van de VervolgOpleidingen' (In VIVO).

In het nieuwe curriculum van de opleiding tot kinderarts, gebaseerd op het opleidingsplan GOED (Generieke Onderwijs en Evaluatie Doelen), wordt de opleiding onderverdeeld in twee fasen: een basisfase van drie jaar en een differentiatiefase van twee jaar. ${ }^{5}$ Het eerste jaar van de differentiatiefase (vierde opleidingsjaar) is voornamelijk bedoeld voor verbreding en verdieping van de competenties binnen de verschillende deelspecialistische modules. In de praktijk komt dit neer op een gestructureerd aanbod van specifieke stages binnen een opleidingscluster waaruit de aios kan kiezen. Het tweede jaar van de differentiatiefase (vijfde opleidingsjaar) is gericht op een verdere verdieping van de persoonlijke leerdoelen van de aios aan de hand van keuzestages. De keuzestages hebben als doel de individuele competenties in het vak optimaal te ontplooien, hetgeen niet alleen het zelfsturend leren van de aios bevordert maar ook ten goede komt aan de kwaliteit van de toekomstige medisch specialist. ${ }^{6}$ Indien deze keuzestage plaatsvindt in het buitenland worden aan de opleidingsinrichting ter plaatse uiteraard dezelfde kwaliteitseisen gesteld als aan de Nederlandse opleidingsinstellingen.

\section{Wat vinden de aios \\ kindergeneeskunde zelf?}

Om te inventariseren of er voldoende interesse bestaat voor een keuzestage in het buitenland en tevens om inzicht te krijgen in de inrichting van een dergelijke stage, werd in januari 2009 per e-mail een enquête verstuurd naar alle 278 kinderartsen in opleiding in Nederland. Het aantal respondenten bedroeg 119 (43\%). Van alle respondenten vindt $99 \%$ dat een buitenlandse stage in de opleiding tot kinderarts van toegevoegde waarde is en $87 \%$ van hen zou daadwerkelijk een stage in het buitenland willen doen als die mogelijkheid bestond. Zo'n stage zou dan bij voorkeur zes maanden moeten duren en $45 \%$ van de respondenten zou opteren voor een keuzestage in een ontwikkelingsland (zie Tabel 1).

\section{Keuzestage kindergeneeskunde in ontwikkelingslanden}

Gezien het toenemend aantal kinderen van allochtone afkomst in ons land, bestaat bij een groot deel van de kinderartsen in opleiding de behoefte aan het eind van de opleiding een keuzestage kindergeneeskunde in een ontwikkelingsland te doen. Door toenemende migratie en globalisering van de gezondheidszorg 
Tabel 1. Resultaten enquête.

\begin{tabular}{llc}
\hline & & $\mathrm{n}=119$ \\
\hline Leeftijd (jr) & Gemiddeld & 30.6 \\
& Mediaan & 31.0 \\
Sekse (\%) & Vrouw & 68.1 \\
& Man & 31.9 \\
Burgerlijke staat (\%) & Alleenstaand & \\
& Samenwonend & 19.5 \\
& Getrouwd & 48.3 \\
& & 32.2 \\
Kinderen (\%) & Ja & \\
& Nee & 27.7 \\
Opleidingsjaar (jr) & Gemiddeld & 72.3 \\
& Mediaan & 2.6 \\
Tijdsduur keuzestage & & 2.5 \\
in het buitenland (\%) & $<6$ maanden & 21.8 \\
& 6 maanden & 68.9 \\
Soort keuzestage (\%) & $>6$ maanden & 9.3 \\
& Niet westers ziekenhuis & 45.5 \\
& Westers ziekenhuis & 32.7 \\
& & 21.8 \\
\hline
\end{tabular}

is immers kennis van importziekten en schaarstegeneeskunde in de Nederlandse context steeds belangrijker geworden. ${ }^{7}$

Een stage kindergeneeskunde in een ontwikkelingsland is bij uitstek een verrijking voor de toekomstige kinderarts omdat alle zeven CanMEDS competenties uitvoerig aan bod kunnen komen. ${ }^{8-9}$ De veelal zeer beperkte middelen in ontwikkelingslanden noodzaken tot het vertrouwen op basale informatie als nauwkeurig lichamelijk onderzoek (medisch handelen) en tot het kritisch stellen van indicaties voor vervolgonderzoek en behandeling (kennis en wetenschap). Het leren omgaan met andere culturen is een ander gevolg van het werken in het buitenland (com- municatie) wat na terugkeer in het eigen land van toegevoegde waarde is in de relatie met allochtone patiënten. Door de vaak krappe personele bezetting in het ontwikkelingsland leert de aios bovendien flexibel te zijn in werkhouding en samenwerking en zal kennisoverdracht aan lokaal zorgpersoneel een belangrijke rol spelen (samenwerking). Ook wordt de aios tijdens een dergelijke stage directer betrokken bij het zorgverleningproces en de levensomstandigheden en gezondheidstoestand van de lokale gemeenschap (maatschappelijk handelen) en kan hij/zij een concrete bijdrage leveren aan de coördinatie en organisatie (organisatie) van het werk in het ziekenhuis. Tenslotte kan 
de confrontatie met de veelal grote verschillen in kansen op goede gezondheid ter plaatse een kritisch en relativerend effect hebben op de perceptie van de problemen in onze eigen westerse samenleving (professionaliteit).

\section{Huidige maatregel terugdraaien}

Met de stopzetting door het ministerie van VWS van de financiering van buitenlandse keuzestages wordt een groot aantal aios kindergeneeskunde in hun opleiding benadeeld. Een keuzestage heeft immers tot doel de individuele competenties optimaal te ontplooien hetgeen ten goede komt aan zowel het zelfsturend leren van de aios als aan de kwaliteit van de toekomstige medisch specialist. In het gemoderniseerde opleidingscurriculum voor de medische vervolgopleidingen wordt aan keuzestages dan ook veel waarde gehecht.

De bovengenoemde financiële maatregel van het ministerie van VWS is ons inziens in tegenspraak met het beleid om de kwaliteit van de medische vervolgopleidingen te verbeteren en zou daarom zo spoedig mogelijk moeten worden herzien.

\section{Naschrift}

Het ministerie van VWS heeft in een recent bericht inmiddels laten weten dat de subsidie voor buitenlandse keuzestages als onderdeel van de specialistenopleiding vanaf 2010, onder voorwaarden, weer zal worden toegekend. Onder deze voorwaarden wordt verstaan: 1) het opleidingsdeel in het buitenland moet tijdig - d.w.z. vóór 31 oktober - zijn vastgelegd in het opleidingsschema en 2) het opleidingsdeel is dan in het jaar daarna in principe subsidiabel voor zover dat niet leidt tot verlenging van de totale opleidingsduur.

Deze berichtgeving is openbaar gemaakt in het toewijzingskader voor de subsidieronde 2010 via de VWS-site: http://www.minvws.nl/dossiers/opleidingsfonds/default.asp.

\section{Literatuur}

1. Staatscourant 14 december 2004, $\mathrm{nr} 241$.

2. Regeling van de Minister van Volksgezondheid, Welzijn en Sport van 13 december 2007, gelet op artikel 3 van de Kaderwet VWS-subsidies.

3. Meyboom-de Jong B, Schmitt Jongbloed C, Willemsen MC. 'De arts van straks', een nieuw medisch opleidingscontinuüm. KNMG; oktober 2002.

4. Le Grand-van den Bogaard M. De zorg van morgen, flexibiliteit \& samenhang. Den Haag: ministerie van VWS en OC\&W; juli 2003.

5. Rapport Generieke Onderwijs en Evaluatie Doelen (GOED) binnen het curriculum van de opleiding tot kinderarts. Utrecht: Nederlandse Vereniging voor Kindergeneeskunde; april 2007.

6. Teunissen PW, Boor K, Scheele F, Kroon CD de, Diemen JAAM van, Vreede I de. Aios aan het roer; laat AIOS zelf hun opleiding inkopen. Med Contact 2007; 62(38):1548-50.

7. de Meer K, Tjon A, Ten W, Wolf B. Werkboek importziekten bij kinderen, Nederlandse Vereniging voor Kindergeneeskunde. Amsterdam: VU uitgeverij; 2000.

8. Moons, P. De voordelen van werken in een ontwikkelingsland tijdens de opleiding tot medisch specialist. Ned Tijdschr Geneeskd 2006;150:2273-6.

9. Busari J, Verhagen E, Muskiet F. The influence of the cultural climate of the training environment on physicians' self-perception of competence and preparedness for practice. BMC Medical Education 2008; 8:51-7.

De auteurs:

Drs. D.H. Visser is aios kindergeneeskunde, VUmc Amsterdam.

Drs. E.A.M. Westerbeek is assistent geneeskundige in opleiding tot klinisch onderzoeker (agiko) kindergeneeskunde, VUmc Amsterdam.

Drs. L.H. Hendrikx, is arts-onderzoeker kindergeneeskunde, Spaarne Ziekenhuis.

Dr. J.O. Busari, is ontwerpleider kindergeneeskunde In VIVO en wrnd. opleider kindergeneeskunde Atrium MC Heerlen.

Dr. B.H.M. Wolf is voormalig tropenarts en opleider kindergeneeskunde, Sint Lucas Andreas Ziekenhuis Amsterdam.

Correspondentieadres:

d.visser@vumc.nl

Belangenconflict: geen gemeld

Financiële ondersteuning: geen gemeld 


\section{Summary}

Programmes of postgraduate specialist training in the Netherlands are currently undergoing reform. In order to finance this reform the Ministry of Health, Welfare and Sport (HWS) set up a special training fund in 2007. However, in 2008, the Ministry withdrew funding for international internships of specialist registrars. This decision made it impossible for a majority of specialist registrars to plan foreign internships during their training. A survey conducted in January 2009 among all paediatric specialist registrars showed that 99\% of the respondents felt that a foreign internship was beneficial for their paediatric specialist training. Most of the respondents disagreed with the decision of the Ministry of HWS, to discontinue the funding of the internships claiming that this was detrimental to the professional training of future specialists. (Visser DH, Westerbeek EAM, Hendrikx LH, Busari JO, Wolf BHM. Plans dropped for international elective internships for specialist registrars? Dutch Journal of Medical Education 2009;28(3):119-123.) 